\title{
Quality of life of mothers whose children work on the streets of São Paulo, Brazil
}

\author{
Qualidade de vida de mães de crianças \\ trabalhadoras de rua da cidade de \\ São Paulo, Brasil
}

\author{
La calidad de vida de las madres de niños \\ trabajadores en las calles de \\ São Paulo, Brasil
}

\begin{abstract}
${ }^{1}$ Departamento de
Psiquiatria, Universidade Federal de São Paulo, São Paulo, Brasil.

2 Instituto de Matemática e Estatística, Universidade de São Paulo, São Paulo, Brasil.

Correspondence

L. P. Cavalcante-Nóbrega

Departamento de Psiquiatria

Universidade Federal de São Paulo.

Rua Borges Lagoa 570, São Paulo, SP 04038-020, Brasil. lpcnobrega@gmail.com
\end{abstract}

\begin{abstract}
The present study evaluated the perceived quality of life of the mothers of street children and investigated the association with their history of childhood violence, the occurrence of current domestic violence, their current mental states and that of their children, and family functioning. The applied instruments were as follows: Strengths and Difficulties Questionnaire, WorldSAFECore Questionnaire, Instrument for the Assessment of Quality of Life of the WHO, Global Assessment of Relational Functioning Scale, Childhood Trauma Questionnaire and $a$ socio-demographic questionnaire. The sample of convenience consisted of 79 low-income mothers who raised their children alone, and most of whom had a positive screening for mental illness. The multiple regression analysis showed that the perception of quality of life of these women was associated with the presence of psychopathology either in themselves or their children and family dysfunction. Thus any program aimed at improving the quality of life of such mothers should consider addressing their mental problems as well as those of their children, besides offering educational and psychotherapeutic approaches to these families to improve the social environment.
\end{abstract}

Quality of Life; Mothers; Homeless Youth;

Domestic Violence
Luciana Porto Cavalcante-Nóbrega 1

Andrea Feijó Mello 1

Mariana Rangel Maciel 1

Giuliana Cláudia Cividanes 1

Victor Fossaluza 2

Jair Jesus Mari 1

Marcelo Feijó Mello ${ }^{1}$

\section{Resumo}

Avaliamos a percepção da qualidade de vida de mães de crianças em situação de rua e investigamos a sua possível associação com os antecedentes maternos de abuso e violência na infância e vitimização atual, sintomas emocionais delas e de seus filhos e com o funcionamento familiar. Foram aplicados os seguintes instrumentos: Instrumento para a Avaliação da Qualidade de Vida da OMS - versão abreviada, Questionário de Capacidades e Dificuldades, WorldSAFECore Questionnaire, Escala de Avaliação Global de Funcionamento nas Relações Familiares, Childhood Trauma Questionnaire e um questionário sociodemográfico. Nossa amostra de conveniência foi constituída por 79 mães, a maioria delas com rastreamento positivo para doença mental. Aplicamos um modelo de regressão múltipla que encontrou associação entre a percepção de pior qualidade de vida com a presença de psicopatologia nelas e em seus filhos e com pior funcionamento familiar. Dessa forma, qualquer programa voltado para a melhora da qualidade de vida de mães nessa condição deve considerar a abordagem de problemas mentais nelas e em seus filhos, além de oferecer recursos educacionais e psicoterapêuticos para as famílias, visando à melhora das condições socioambientais.

Qualidade de Vida; Mães; Menores de Rua; Violência Doméstica 


\section{Introduction}

Quality of life is defined by the World Health Organization (WHO) as an "individual's perception of their position in life in the context of the culture and value systems in which they live and in relation to their goals, expectations, standards and concerns" 1 (p. 299). This is a broad ranging concept affected by the person's physical health, psychological state, level of independence, social relationships, personal beliefs and their environment context. The WHO proposes that when creating a scale to evaluate quality of life, a subjective, multidimensional concept should be employed that includes both positive and negative elements of evaluation and inserts the subjectivity of the construct into the cultural, social and environmental context 1,2 .

The quality of life of mothers is something that has not yet been explored extensively. According to a review carried out in 2009, only 17 articles were focused on mothers' health related to quality of life and included some physical and emotional evaluations, while there were no publications in relation to the quality of life of mothers in the general population. After this period nothing else was added. Researchers found that maternal demands (maternal or child health or disability) and environmental elements (poverty, social support) are related to their quality of life. Limited knowledge does not make this issue less relevant, since the quality of their lives begins to influence their abilities to develop internal resources to take care of themselves and their families 3,4 .

Mothers living in a context of poverty and domestic violence, with mental health problems, are strongly associated with a higher percentage of positive screening for mental illness in children ${ }^{5}$. In addition, mothers who experienced abuse during childhood are more likely to physically abuse their children 6,7 . Both the history of childhood abuse and current victimization have a negative impact on mothering, making these mothers less tolerant and more inclined to use more basic educational methods or to be less aware and less connected to their children 7. On the other hand, mothers without a history of childhood abuse have a better sense of wellbeing that is directly related to the neuropsychomotor development of preschool-aged children 8 . A structured and organized family environment that does not have a large number of individuals under the same roof contributes to the development of resilient children ${ }^{9}$.

In Brazil, the presence of children working on the streets (e.g., juggling and selling sweets at traffic lights or collecting cans for recycling) is shocking and has led public authorities and some non-profit organizations to develop programs for its eradication. Studies show that most of these youth maintain family bonds 10,11. They belong to low-income families that are headed mostly by women and marked by a history of violence, drug use and unemployment 11. So such families become an important focus for attention in countries where there are huge social differences. However, a systematic review of the effectiveness of interventions with young people on the streets found that quality of life as an outcome measure has received little attention 12 .

The objective of the current study was to evaluate the perceived quality of life of the mothers of a group of street children and associate it with the mothers' history of childhood violence, the occurrence of current domestic violence, their mental states and that of their children, and family functioning.

\section{Methods}

Sample

This was a cross-sectional study that used a non-probability sample of convenience, consisting of mothers of children aged between 7 and 14 years who worked on the streets. These children were recruited from a program that was implemented by the São Paulo Municipal Government to combat child labor. Social welfare workers approached a group of children who were selling items such as candy at traffic lights and sent them to an Non-governanmental Organization (NGO) called the Rukha Institute for a two-year assistance program called Projeto Virada. Their families were then located, identified and invited to participate in the program. The program has a family approach that aims to recover family bonds and promote autonomy. It is based on providing the children and their families with resources to re-build their lives. The main objective is to help children leave the streets and begin attending school regularly. Tools such as support at cultural workshops, psychological and psychiatric care (if necessary), and assistance are offered to help parents become economically self-sufficient. The families also receive welfare from the NGO to replace the income generated by the children's work on the streets.

After agreeing to join the program, the caregiver responsible for the children signed the informed consent form to participate in the study. The research protocol was approved by the Ethics 
Research Committee of the Federal University of São Paulo (n. CEP 0550/08).

The scales that will be mentioned in the next section were applied by trained interviewers, when the families entered the program, between October 2008 and March 2009.

79 of the mothers who presented themselves as a principal caregiver of the child in the group of 83 families were included. Four families in which the main caregiver was someone other than the mother, were excluded.

\section{Assessment tools}

We used the following instruments:

(1) Sociodemographic inventory. An instrument to assess the sociodemographic characteristics of the sample was created with the following information: (a) identification of the child or adolescent and his/her guardian (name, age, date of birth, sex, nationality, race, marital status, religion, income, education and occupation), (b) determination of the relational environment of the child or adolescent (number of people living in the same house and relational role with respect to the child or adolescent), (c) health status of the child or adolescent and medical history (hospital and medical treatment, including psychological or educational treatment, current and in the past six months, and the occurrence of a physical or mental disability). With respect to socioeconomic distribution the classification of the Brazilian Association of Research Companies (ABEP; http://www.abep.org/criterioBrasil.aspx, accessed on 23/Oct/2014) was used, which assesses various items such as education, housing, income and ownership of assets.

(2) Strengths and Difficulties Questionnaire (SDQ). The SDQ is a screening instrument for child mental health problems. It consists of five scales that address emotional symptoms, behavior problems, hyperactivity, poor peer relationships and prosocial behavior. It also provides a measure of the impact of the symptoms on the child's functioning. The three existing versions (for parents, teachers and young people from age 11) are self-administered and differ only in a few terms. They are currently being validated for the Brazilian population. A cut-off point of 14 was used to identify children with mental health problems 13

(3) WorldSAFECore Questionnaire (sections D and F). It is a standardized instrument that contains questions related to intra-familial violence and associated factors. The original English questionnaire was developed by the WorldSAFE steering committee and copyrighted in 1998. The Brazilian version was based on a consensus among WorldSAFE steering committee members, including questions about behaviors also observed in countries such as Chile, Egypt, India, and the United States 14. Section D investigates possible physical aggression or death threats suffered by the mothers and inflicted by their partners in the past 12 months. The five questions were: slapping, punching, kicking, beating and threatening with a weapon. These data were used in the descriptive analysis to characterize the occurrence of current domestic violence. In the regression analyses the variable "aggression inflicted by partner" was a categorical variable and a single affirmative answer given to one of the five questions mentioned above would categorize the mother as having suffered domestic violence. Section F evaluates the mental health of the mother through the Self Report Questionnaire (SRQ). The SRQ is used to identify psychiatric disorders at the primary care level. It consists of 20 questions that detect emotional symptoms. A person with eight or more positive answers is considered a possible case. This cutoff point was obtained by determining the sensitivity, specificity and positive and negative predictive values in a validation study conducted in Brazil 15 . This cut-off was used in the descriptive analysis to characterize the mothers into two groups about the presence, or otherwise, of depressive-anxious symptoms. However, in the regression model the variable "presence of emotional symptoms in the mother" was continuously analyzed by the total amount of affirmative answers.

(4) Instrument for the Assessment of Quality of Life of the World Health Organization (WHO QOL-Bref). We used the abbreviated version of the WHO's quality of life assessment validated in Portuguese. The questionnaire is self-administered and consists of 26 questions. The two initial questions are general questions: "How do you evaluate your quality of life?" and "How satisfied are you with your health?". The other 24 address four aspects of quality of life (in the physical, psychological, social and environmental domains) experienced by the mother in the past two weeks. Scores range from 0 to 100 , with higher values corresponding to a better quality of life 16,17.

(5) Global Assessment of Relational Functioning Scale (GARF). This instrument consists of a semistructured family interview validated into Portuguese. This interview addresses the following aspects of family functioning: (a) problem solving, i.e., negotiating and communication skills, and objectivity in problem solving, (b) organization of relational roles, ability to differentiate and maintain roles, establish and maintain limits of authority, power and responsibility, (c) emotional climate, tone and range of feelings, reciprocity 
in relations and attachment/commitment levels, quality of caring, empathy, affective responsiveness and expression of affection. The GARF ranges from 0 to 100 points, divided as follows: 1 to 20 - relational unit has become too dysfunctional to retain continuity of contact and bonding; 21 to 40 - relational unit is obviously and seriously dysfunctional, forms and time periods of satisfactory relating are rare; 41 to 60 - relational unit has occasional moments of satisfying and competent functioning together, but a clearly dysfunctional, unsatisfying relationship tends to predominate; 61 to 80 - functioning of relational unit is somewhat unsatisfactory over a period of time, many but not all difficulties are resolved without complaints; 81 to 100 - relational unit is functioning satisfactorily 18 . These categories were used in the descriptive analysis, however the variable "family functioning" was continuously analyzed for the purpose of the regression model.

(6) Questionnaires on exposure to traumatic events (CTQ/QUESI). The CTQ (Childhood Trauma Questionnaire) addresses childhood exposure to traumatic events related to abuse (emotional, physical and sexual), and negligence (emotional and physical). This questionnaire was originally developed for children ages 12 and over 19. The Questionário Sobre Traumas na Infância (QUESI) is the adapted version for Brazil for children over 12 years, which was validated into Portuguese 20. This categorical variable "mother's history of abuse and neglect" was used both in the descriptive analysis and the regression.

\section{Statistical analysis}

In order to characterize the sample and evaluate the perceived quality of life a descriptive analysis was carried out. Sociodemographic data (age, schooling, family income, religion, number of children, occupational and marital status) and the mother's history of early childhood abuse, exposure to domestic violence, presence of depressive-anxious symptoms, family functioning and the child's mental state were analyzed using percentages, averages and standard deviation. In the descriptive analysis of quality of life, average scores of four domains (physical, psychological, social and environment) as well as the overall average score (WHOQOL) were considered.

The categorical variables were compared using the chi-square test and the numerical variables using the Mann-Whitney nonparametric test. We calculated a 95\% confidence interval.

In order to identify the eventual factors related to the mother's quality of life, our dependent variable, the linear multiple regression model consisted both of several independent categori- cal variables, as follows: aggression inflicted by partner (section D - WorldSAFE), mother's history of abuse and negligence (QUESI), and children's mental health problems (SDQ); and of numerical independent variables: family functioning (GARF), presence of emotional symptoms in the mother (SRQ), and number of children. For regression purposes, a stepwise selection model was used to exclude variables that were not significant 21 .

\section{Results}

The sample consisted of 79 low-income adult women who were mostly single and heads of their families, black and brown, living in poor housing conditions and sharing a room with six people, with some houses lodging up to 14 residents. The women had an average of four children, with the number ranging from 1 to 10 . With respect to socioeconomic distribution, $31 \%$ belonged to the $\mathrm{C}$ bracket of society or low-middle class, $59 \%$ to bracket $\mathrm{D}$, and $9 \%$ to bracket $\mathrm{E}$, the lowest income bracket of society (Table 1).

The mothers' history of early childhood abuse, exposure to domestic violence such as severe beatings inflicted by their companions, and the presence of emotional symptoms are alarming, as pointed out in Table 2 .

The GARF average overall score was 49.41 (SD 21.21), which represents a dysfunctional family with a predominance of unsatisfactory relationships. $73.4 \%$ of the children had a positive screening for mental illness, and the SDQ average total score was 19.18 (SD 6.27).

The data from the two initial questions of the WHOQOL-Bref show that when asked to evaluate their quality of life generally, the percentages of the mothers that answered that it was "good" was $12 \%$, as "neither good nor bad" $61.3 \%$, as "bad" $21.3 \%$ and only $5.3 \%$ responded "very bad". No mother evaluated their quality of life to be "very good". Similar percentages were observed with respect to satisfaction with their health: $16 \%$ of mothers answered "very satisfied", $26.7 \%$ "satisfied", $37.3 \%$ as "neither satisfied nor dissatisfied", $16 \%$ as "dissatisfied" and $4 \%$ as "very dissatisfied". Table 3 shows scores, converted into 0-100 scale, in each domain and total score for quality of life.

The multiple regression model showed that the general level of quality of life was associated with the mothers' mental health, namely the presence of emotional symptoms (estimate $=$ -0.866 , standard error $=0.409$, $\mathrm{p}$-value $=0.038$ ) Furthermore, there was a significant association between their children's mental state and the mothers' mental state (estimate $=0.324$, standard 
Table 1

General characteristics of the sample.

\begin{tabular}{lcc}
\hline Variables & Average & SD \\
\hline Age & 35.29 & 5.71 \\
Schooling (years of study) & 5.70 & 3.44 \\
Number of children & 4.21 & 1.88 \\
Total number of residents per household & 6.01 & 2.33 \\
Family income (in BRL) & 380.77 & 248.86 \\
\hline
\end{tabular}

Skin color
White
Brown
Black
Marital status
Single
Married/Cohabitating
Separated/Divorced
Widower
Religion
Catholic
Spiritist
Evangelical
Atheist
Other
Does the mother have a paid job?
No
Yes

n

$\%$

$\begin{array}{cc}17 & 22.7 \\ 32 & 42.7 \\ 26 & 34.7 \\ & \\ 54 & 71.1 \\ 17 & 22.4 \\ 1 & 1.3 \\ 4 & 5.3 \\ & \\ 41 & 53.9 \\ 1 & 1.3 \\ 30 & 39.5 \\ 1 & 1.3 \\ 3 & 3.9 \\ & \\ 39 & 49.4 \\ 40 & 50.6\end{array}$

SD: standard deviation.

error $=0.079, \mathrm{p}$-value $<0.001)$. The family state, such as the level of functioning and the family composition (number of children), was only associated with psychological and social domains, described below. Furthermore, the current violence inflicted by the partners and experience of abuse and negligence in childhood were not associated with the mother's quality of life.

The presence of emotional symptoms in the mothers was negatively associated with the psychological (estimate $=-1.704$; standard error $=0.388$; -value $<0.001)$, physical (estimate $=$ -1.859 ; standard error $=0.375$; $\mathrm{p}$-value $<0.001$ ) and environmental (estimate $=-1.112$; standard error $=0.278$; $p$-value $<0.001$ ) domains. There was no association with the social aspect of quality of life. Having at least one child with a positive screening for emotional problems (anxiety/ depression), behavior or relational problems, hyperactivity and attention deficit disorder was associated with lower levels of the mother's physical and psychological quality of life.
Regarding the number of children, there was a positive association with the aspect of social relations (estimate $=3.203$; standard error $=$ $1.300 ; \mathrm{p}$-value $=0.016$ ). Thus, as the number of children increased, the mother's satisfaction with personal relationships (friends, relatives, acquaintances, colleagues), support received from friends and sex life increased. The percentage of mothers who stated that they were satisfied or very satisfied in the answers to these questions was $50.7 \%, 42.4 \%$ and $30.6 \%$, respectively.

Family functioning was associated with the social aspect of quality of life (estimate $=0.261$; standard error $=0.101 ; \mathrm{p}$-value $=0.013$ ) .

Analyses were also conducted by dividing the mothers into two groups according to whether they screened positive or negative for emotional symptoms. Regarding their perceived quality of life, mothers with anxiety-depressive symptoms scored the lowest in all domains except in the social domain (Table 4). 
History of abuse and neglect, exposure to violence and emotional symptoms.

\begin{tabular}{|c|c|c|}
\hline & $n$ & $\%$ \\
\hline \multicolumn{3}{|c|}{ Emotional abuse } \\
\hline No & 24 & 33.3 \\
\hline Yes & 48 & 66.7 \\
\hline \multicolumn{3}{|c|}{ Physical abuse } \\
\hline No & 34 & 47.2 \\
\hline Yes & 38 & 52.8 \\
\hline \multicolumn{3}{|c|}{ Sexual abuse } \\
\hline No & 48 & 70.6 \\
\hline Yes & 20 & 29.4 \\
\hline \multicolumn{3}{|c|}{ Emotional neglect } \\
\hline No & 24 & 33.8 \\
\hline Yes & 47 & 66.2 \\
\hline \multicolumn{3}{|c|}{ Physical neglect } \\
\hline No & 18 & 26.9 \\
\hline Yes & 49 & 73.1 \\
\hline \multicolumn{3}{|c|}{ Assaults inflicted by a partner (slapping, punching, kicking, beating, threatening with a weapon) } \\
\hline No & 61 & 78.2 \\
\hline Yes & 17 & 21.8 \\
\hline \multicolumn{3}{|c|}{ Presence of depressive anxious symptoms } \\
\hline No & 38 & 48.1 \\
\hline Yes & 41 & 51.9 \\
\hline
\end{tabular}

Table 3

Scores measured by the Instrument for the Assessment of Quality of Life of the World Health Organization (WHOQOL-Bref).

\begin{tabular}{lll}
\hline Domains & Average & SD \\
\hline Physical & 62.72 & 17.62 \\
Psychological & 53.41 & 18.10 \\
Social & 53.77 & 20.39 \\
Environment & 35.88 & 12.50 \\
Overall quality of life & 51.83 & 17.16 \\
\hline
\end{tabular}

SD: standard deviation.

\section{Discussion}

Our quest to understand better mothers who allow and even encourage their children to work on the streets led us to a sample of women living in a state of poverty: $68 \%$ in the poverty bracket $\mathrm{D}$ and bracket $\mathrm{E}$, the lowest income bracket of society. The general population distribution in the metropolitan region of São Paulo was as follows:
48.7\%, $13.8 \%$ and $0.6 \%$ for income brackets C, D and E, respectively (ABEP; http://www.abep.org/ criterioBrasil.aspx, accessed on 23/Oct/2014). The women in the current sample raised their children alone, and most of them were the head of their families. They had low educational levels, and an alarming prevalence of physical, sexual and emotional abuse and physical and emotional negligence during childhood. They also had high rates of severe domestic violence perpetrated by their partners. Over half of them displayed depression and anxiety symptoms. Their families included numerous individuals, living in poor housing, often in just one room. The data showed an alarming prevalence of mental problems in most of the children and dysfunctional family relations.

The overall score of perception of quality of life was lower than that found in studies conducted with the general population in Brazil 22 and with mothers of children with pervasive developmental disorders or serious illnesses such as thalassemia 23,24 .

The physical aspect of quality of life showed the greatest satisfaction level. It was the only aspect that surpassed the level of a sample of mothers of children with pervasive developmental 
Difference in quality of life among mothers with positive and negative screening for emotional problems.

\begin{tabular}{lccccc}
\hline Aspects & \multicolumn{2}{c}{ SRO negative $(\mathrm{n}=35)$} & \multicolumn{2}{c}{ SRO positive $(\mathrm{n}=\mathbf{4 0})$} & $\mathrm{p}$-value \\
& Average & SD & Average & SD \\
\hline Physical & 71.45 & 13.79 & 55.09 & 17.19 & 0.00004 \\
Psychological & 62.43 & 18.04 & 45.52 & 14.18 & 0.00000 \\
Social & 58.70 & 20.88 & 49.58 & 19.24 & 0.06984 \\
Environmental & 40.87 & 12.89 & 31.52 & 10.48 & 0.00279 \\
Overall quality of life & 56.79 & 15.26 & 47.50 & 17.72 & 0.00738 \\
\hline
\end{tabular}

SD: standard deviation; SRQ: Self-Report Questionnaire.

disorders 24 and mothers of children with thalassemia 23. However, the same was not observed when compared to a study with Brazilian mothers of children with autism 25 . It remained lower than in patients with severe psychiatric disorders such as the affective psychoses 26 and caregivers of patients with dementia 27 .

Psychological wellbeing was lower than that of mothers of healthy children and that of mothers of children with serious mental and clinical illnesses $23,24,25$. When considering the mothers with positive screening for emotional symptoms, the raw score was equal to that presented by psychotic patients with major depression 26 .

With regard to the aspect of social relations no difference was found between the mothers with positive and negative screening for emotional symptoms. Mothers with positive screening had lower scores than patients with psychotic conditions and comorbidity with major depressive disorders, drug dependence and personality disorders 26 and mothers of children with delayed psychomotor development 24,25.

The environmental aspect of quality of life showed the lowest scores, below that of mothers of healthy children and that of mothers of children with serious mental and clinical illnesses $23,24,25$, even when considering emotionally healthy mothers.

Of note, mothers' perceptions of quality of life in the present data was worse than that of mothers with children suffering from serious medical problems such as pervasive developmental disorders and thalassemia. These mothers from the current study were also exposed to a high level of stress. However, as mentioned above, there is a shortage of studies about quality of life both in the general population and those in a state of vulnerability.

As expected, the perception of quality of life of these women was significantly associated with the presence of emotional symptoms either in themselves $28,29,30,31$ or their children 32 . The presence of anxiety and depressive symptoms in the mothers was significantly associated with worse quality of life in the physical, psychological and environmental domains. The presence of mental problems in their children worsened their perception of quality of life in the physical and psychological aspects. Nonetheless, because there was a strong association between mental symptoms in mothers and children 30,33,34, we cannot discriminate the role of each of these factors in this result and can only state that they significantly worsen the mothers' quality of life.

Regarding the number of children, we found an association in the same direction with the perceived quality of life in the social relations aspect. This result was not verified in a previous study with Brazilian families with only two to three children, on average 25 . This finding may reflect the fact that the children and adolescents in the current sample participate in home care and support, as previously described in economically disadvantaged families 10 .

Although the presence of domestic violence and abuse during childhood were not associated with the mothers' perceived quality of life in our findings, current scientific evidence shows that both factors are important risk factors for the presence of psychopathology 35. Moreover, studies in populations other than that of mothers, namely women with a self-reported history of abuse or who are currently abused by their partners, provide evidence for an association between such factors and lower levels of quality of life $36,37,38$.

The current study has limitations. The sample is one of convenience (i.e., families who entered an assistance program conducted by a nongovernmental organization). Thus, the data cannot be extrapolated to the population as a whole. 
Of the universe of families that were invited to participate in the Projeto Virada, we only evaluated those who accepted. Actually the geographical conditions and the urban area where these families live greatly complicate their assessment, and we could conduct this research only with the help of the Rukha Institute's work in the community. Another issue in respect to the data refers to the recall bias in relation to the abuses during the mothers' childhood, longitudinal studies would investigate such a subject in a better way. No foresight studies have been conducted in this population in Brazil; nonetheless, they are greatly needed.

\section{Conclusion}

The mothers of children who work on the streets of the city of São Paulo and their children showed alarming levels of mental symptoms, self-reported abuse history and current domestic violence. Their perceived quality of life shows lower levels compared to women in other studies with underprivileged populations or with mothers of children with serious illnesses, even when considering mothers without symptoms of anxiety and depression. Thus, any program aimed at eradicating child labor on the streets should consider a medical and psychological intervention that addresses the mental disorders that affect both the children and their mothers. Educational and psychotherapeutic work with these dysfunctional families is needed, as long as improvement in social economic conditions is also provided. Only through addressing these issues, will we see an improvement in their quality of life, which may in turn break the cycle of violence. 


\section{Resumen}

Se presenta aquí una evaluación de la calidad de vida percibida madres de niños en las calles, y se investigó la posible asociación con antecedentes maternos de abuso y violencia en la infancia y victimización actual, los síntomas emocionales de ellos y de sus hijos y el funcionamiento familiar. Se aplicaron los Instrumentos para la Evaluación de la Calidad de Vida de la OMS - versión abreviada, Cuestionario de Capacidades y Dificultades, WorldSAFECore Questionnaire, Escala de Evaluación Global de Funcionamiento en las Relaciones Familiares, Childhood Trauma Questionnaire y un cuestionario sociodemográfico. La muestra incluyó a 79 madres, la mayoría de ellas con una detección positiva para la enfermedad mental. La percepción de calidad de vida se asoció con la presencia de psicopatología en ellos y sus hijos y el funcionamiento familiar. Por lo tanto, cualquier programa destinado a mejorar la calidad de vida de las madres en esta condición debe considerar el enfoque de los problemas mentales en ellos y sus hijos y ofrecer trabajo educativo y terapéutico a esas familias.

Calidad de Vida; Madres; Jóvenes sin Hogar; Violencia Doméstica

\section{Contributors}

L. P. Cavalcante-Nóbrega participated in the conception and design of the article, analysis and data interpretation, drafting and approval of the final version. A. F. Mello participated in the conception and design of the article, analysis and data interpretation, writing, reviewing and approval of the final version. M. R. Maciel and G. C. Cividanes contributed towards the analysis and data interpretation, review and approval of the final version. V. Fossaluza participated in the statistical analysis and data interpretation, review and approval of the final version. J. J. Mari helped in the design, critical review and approval of the final version. M. F. Mello participated in the conception and design of the article, data interpretation, writing, reviewing and approving the final version.

\section{Acknowledgments}

We thank the Rukha Institute and the Neuropsychoanalysis Research Center (CEINP), in particular its founders, Yusaku Soussumi and Sonia P. Soussumi, who enabled the research to be carried out.

\section{References}

1. Skevington SM, Lofty M, O'Connel KA. The World Health Organization's WHOQOL-BREF quality of life assessment: psychometric properties and results of the international field trial. A Report from the WHOQOL Group. Qual Life Res 2004; 13:299-310.

2. Berlim MT, Fleck MPA. Quality of life: a brand new concept for research and practice in psychiatry. Rev Bras Psiquiatr 2003; 25:249-52.

3. Coyle SB. Health-related quality of life of mothers: a review of the research. Health Care Women Int 2009; 30:484-506.

4. Vuori A, Astedt-Kurki P. Well-being of mothers with children in Finnish low-income families: the mother's point of view. Scand J Caring Sci 2009; 23:748-56

5. Fleitlich BW, Goodman R. Social factors associated with child mental health problems in Brazil: cross sectional survey. BMJ 2001; 323:599-600.
6. Bordin IAS, Paula CS, Nascimento R, Duarte CS. Severe physical punishment and mental health problems in an economically disadvantaged population of children and adolescents. Rev Bras Psiquiatr 2006; 28:290-6.

7. Dubowitz H, Black MM, Kerr MA, Hussey JM, Morrel TM, Everson MD, et al. Type and timing of mothers' victimization: effects on mothers and children. Pediatrics 2001; 107:728-35.

8. Tough SC, Siever JE, Benzies K, Leew S, Johnston DW. Maternal well-being and its association to risk of developmental problems in children at school entry. BMC Pediatr 2010; 10:19.

9. Mandleco BL, Peery JC. An organizational framework for conceptualizing resilience in children. J Child Adolesc Psychiatr Nurs 2000; 13:99-111.

10. Paludo SS, Koller SH. Toda criança tem família: criança em situação de rua também. Psicol Soc (Impr) 2008; 20:42-52. 
11. Abdelgalil S, Gurgel RQ, Theobald S, Cuevas LE. Household and family characteristics of street children in Aracaju, Brazil. Arch Dis Child 2004; 89:817-20.

12. Altena AM, Brilleslijper-Kater SN, Wolf J. Effective interventions for homeless youth: a systematic review. Am J Prev Med 2010; 38:637-45.

13. Fleitlich BW, Cortazar PG, Goodman R. Questionário de capacidades e dificuldades (SDQ). Infanto Rev Neuropsiquiatr Infanc Adolesc 2000; 8:44-50.

14. Bordin IA, Paula CS. Estudos populacionais sobre saúde mental de crianças e adolescentes brasileiros. In: Mello M, Kohn R, organizadores. Epidemiologia da saúde mental no Brasil. Porto Alegre: Artes Médicas; 2006. p. 101-17.

15. Mari JJ, Williams P. A validity study of a psychiatric screening questionnaire (SRQ-20) in primary care in the city of Sao Paulo. Br J Psychiatry 1986; 148:23-6.

16. Fleck MP, Louzada S, Xavier M, Chachamovich E, Vieira G, Santos L, et al. Application of the Portuguese version of the abbreviated instrument of quality life WHOQOL-bref. Rev Saúde Pública 2000; 34:178-83.

17. Division of Mental Health and Prevention of Substance Abuse, World Health Organization. WHOQOL user manual. Geneva: World Health Organization; 1988

18. Mello AF, Blay SL, Kohn R. Global Assessment of Relational Functioning Scale (GARF): a validity study in patients with recurrent major depression in Brazil. Transcult Psychiatry 2007; 44:55-64.

19. Bernstein DP, Fink L, Handelsman L, Foote J, Lovejoy $\mathrm{M}$, Wenzel $\mathrm{K}$, et al. Initial reliability and validity of a new retrospective measure of child abuse and neglect. Am J Psychiatry 1994; 151:1132-6.

20. Grassi-Oliveira R, Stein LM, Pezzi JC. Translation and content validation of the Childhood Trauma Questionnaire into Portuguese language. Rev Saúde Pública 2006; 40:249-55.

21. Neter J, Kutner MH, Nachtsheim CJ, Wasserman W. Applied linear regression models. Homewood: Irwin; 1996.

22. Paes ILB, Biazevic MGH, Michel-Crossato E. Qualidade de vida da população de Treze Tílias-SC, Brasil: um estudo censitário domiciliar. Odontologia e Sociedade 2008; 10:1-7.

23. Mazzone L, Battaglia L, Andreozzi F, Romeo MA, Mazzone D. Emotional impact in beta-thalassaemia major children following cognitive-behavioural family therapy and quality of life of caregiving mothers. Clin Pract Epidemiol Ment Health 2009; 5:5.

24. Mugno D, Ruta L, D’Arrigo VG, Mazzone L. Impairment of quality of life in parents of children and adolescents with pervasive developmental disorder. Health Qual Life Outcomes 2007; 5:22.

25. Favero-Nunes MA, Santos MA. Depression and quality of life in mothers of children with pervasive developmental disorders. Rev Latinoam Enferm 2010; 18:33-40.
26. Cotton SM, Gleeson JF, Alvarez-Jimenez M, McGorry PD. Quality of life in patients who have remitted from their first episode of psychosis. Schizophr Res 2010; 121:259-65.

27. Guerra M, Ferri CP, Fonseca M, Banerjee S, Prince M. Helping carers to care: the 10/66 dementia research group's randomized control trial of a caregiver intervention in Peru. Rev Bras Psiquiatr 2010; 33:47-54.

28. Aigner M, Forster-Streffleur S, Prause W, Freidl M, Weiss M, Bach M. What does the WHOQOL-Bref measure? Measurement overlap between quality of life and depressive symptomatology in chronic somatoform pain disorder. Soc Psychiatr Epidemiol 2006; 41:81-6.

29. Berlim MT, McGirr A, FleckMP. Can sociodemographic and clinical variables predict the quality of life of outpatients with major depression? Psychiatry Res 2008; 160:364-71.

30. Ferriolli SH, Marturano EM, Puntel LP. Family context and child mental health problems in the Family Health Program. Rev Saúde Pública 2007; 41:251-9.

31. Darcy JM, Grzywacz JG, Stephens RL, Leng I, Clinch CR, Arcury TA. Maternal depressive symptpmatology: 16-month follow-up of infant and maternal-related qualitty of life. J Am Board Fam Med 2011; 24:249-57.

32. Maciel MR, Mello AF, Fossaluza V, Nobrega LP, Cividanes GC, Mari JJ, et al. Children working on the streets in Brazil: predictors of mental health problems. Eur Child Adolesc Psychiatry 2013; 22:16575.

33. Feder A, Alonso A, Tang M, Liriano W, Warner V, Pilowsky D, et al. Children of low-income depressed mothers: psychiatric disorders and social adjustment. Depress Anxiety 2009; 26:513-20.

34. Guethmundsson OO, Tomasson K. Quality of life and mental health of parents of children with mental health problems. Nord J Psychiatry 2002; 56:413-7.

35. Mello MF, Faria AA, Mello AF, Carpenter LL, Tyrka AR, Price LH. Childhood maltreatment and adult psychopathology: pathways to hypothalamicpituitary-adrenal axis dysfunction. Rev Bras Psiquiatr 2009; 31 Suppl 2:41-8.

36. Alsaker K, Moen BE, Nortvedt MW, Baste V. Low health-related quality of life aong abused women. Qual Life Res 2006; 15:959-65.

37. Adeodato VG, Carvalho RR, Siqueira VR, Souza FGM. Quality of life and depression in women abused by theis partners. Rev Saúde Pública 2005; 39:108-13

38. Costa D, Hatzidimitriadou E, Ioannidi-Kapolou E, Lindert J, Soares J, Sundin O, et al. Intimate partner violence and health-related quality of life in European men and women: findings from DOVE study. Qual Life Res 2015; 24:463-71.

Submitted on $26 / \mathrm{Feb} / 2014$

Final version resubmitted on 29/Oct/2014

Approved on 10/Nov/2014 